\title{
Risk Factors Associated With Depression And Anxiety In Older Adults Of Mexican Origin
}

\author{
Dr. Raquel E. Gonzalez \\ Deer Oaks Behavioral Health Organization, Laredo, TX \\ Dr. Magy Martin \\ Walden University, Minneapolis, Minnesota \\ Dr. Don Martin \\ Youngstown State University, Youngstown, Ohio
}

doi: 10.19044/esj.2016.v12n24p1 URL:http://dx.doi.org/10.19044/esj.2016.v12n24p1

\begin{abstract}
Older adults of Mexican origin are often underserved, especially those residing in nursing homes. The purpose of this study was to examine if there was a relationship among risk factors associated with depression and anxiety in older adults of Mexican origin. Using a quantitative correlational design, the relationships were assessed with a demographic questionnaire, the Geriatric Depression Scale (GDS), and the Beck Anxiety Inventory (BAI). A sample of 150 elders of Mexican origin residing in nursing homes in a Texas-Mexico border city were examined using two multiple regression analyses. Data analysis indicated that there was a relationship between risk factors associated with depression and anxiety. Data from this study confirmed that a high score on ADLs predicted greater depression and anxiety while female gender predicted higher anxiety and frequent family support predicted low anxiety.
\end{abstract}

Keywords: Risk factors, older adults, depression, anxiety, nursing homes

\section{Introduction}

In recent years, older adults have received more attention from various professions, but the demand for mental health and health care services is greater than the availability of professionals (Karel et al., 2012). According to the U.S. Department of Health and Human Services (DHHS, 2009), Administration on Aging, 38.9 million Americans are 65 and over, and that number is projected to double in the next 40 years. Currently, older adults constitute $12.8 \%$ of the U.S. population (Cummings, Kropf, Cassie, \& Bride, 2004). The percentage of individuals in nursing homes or other longterm care facilities is $5 \%$ (Tatchell, Jordan, Waite, \& Tatchell, 2003). Two 
million elders live in nursing homes, and more than 1.5 million older adults reside in assisted-living facilities; these numbers are expected to double by 2020 (National Institutes of Health [NIH], 2002). As a result of these placements, older adults must adjust to lives of loss and abandonment associated with institutional placement, physical disabilities, and emotional distress (Brandburg, Symes, Mastel-Smith, Hersch, \& Walsh, 2013). Therefore, various professionals must gain the fundamental knowledge regarding effective strategies that will promote quality of life through a multimodal treatment process that addresses medical, functional, and cognitive disorders, in addition to treatment of late-life mental health disorders (Cummings et al., 2004).

By 2050, 58\% of elderly individuals will be members of an ethnic minority group, with $20 \%$ being Hispanic. The older Hispanic population is expected to grow dramatically "from under 3 million in 2010 to 17.5 million in 2050" (Federal Interagency Forum on Aging-Related Statistics, 2012, p. 4). These statistics are representative of the nation overall, but in Texas, the Texas State Data Center projected increase from 2.6 million in 2011 to 7.5 million in 2040 for the population aged 65 and older (Texas Health and Human Services System [THHSS], 2010). Also, the State Data Center projected the Hispanic population will increase from 530,000 in 2011 to 2.7 million in 2040, which is approximately 422\% (THHSS, 2010).

Texas has the second largest aging Hispanic population and this population will continue to rise in the future (Texas Department of Aging [TDoA], 2002). By 2040, half of the state's elderly population will consist of members of ethnic minority groups. The burgeoning majority of themprimarily Spanish speaking-currently reside in the state's southern counties and along the Texas-Mexico border, where they comprise $13 \%$ of the total population. The federal government has deemed all counties along the Texas-Mexico border to be medically underserved, which includes mental health (TDoA, 2002), and thus makes this study necessary and significant. Hispanic elders are the fastest growing population. Their use of long-term care facilities significantly differs from that of non-Hispanic White elders. When residing in nursing homes, their overall functional status also differs from those of non-Hispanic White elders (Choido, Kanten, Gerety, Mulrow, \& Cornell, 1994). Mexican American elders in nursing homes are more likely to experience higher levels of impairment in cognition and physical functioning compared to non-Hispanic Whites (Choido et al., 1994). For example, a South Texas study determined that the activities of daily living (ADLs) scores for Mexican-American nursing home residents were worse than those of non-Hispanic Whites, as the Mexican Americans were more dependent on assistance for ADLs (Mulrow, Choido, Gerety, Basu, \& Nelson, 1996). 
In long-term settings such as nursing homes, mental health services are essential, especially for ethnic minority older adults. The literature on the effectiveness of various psychological treatment modalities for ethnic minority groups - as well as the risk factors associated with anxiety and depression, specifically among elders of Mexican origin (Chavez-Korell et al., 2012; Vink, Aartsen, \& Schoevers, 2008)—is limited. While the need is significant; too few mental health professionals from ethnic and non-ethnic minority groups are interested in geropsychology (Karel et al., 2012). To increase awareness of mental health and the need for psychological services among the aging population, this study sought to determine the risk factors associated with depression and anxiety in older adults of Mexican origin residing in nursing homes. Furthermore, researchers could then compare these results to those from studies of non-ethnic community-dwelling older adults to determine both commonalities and generalizability.

Depression affects 2 million Americans over the age of 65 (Kieffer \& Reese, 2002), especially those residing in nursing homes (12 to 18\%)(E. D. Jones \& Beck-Little, 2002). Depression in older adults contributes to increased mortality and negatively affects their overall well-being and daily functioning (Kieffer \& Reese, 2002). Anxiety is also common in later life; it has been linked to a physical disability, self-reported increased health complications, and reduced quality of life, as well as frequent access to medical specialists and benzodiazepine medications (Le Roux, Gatz, \& Wetherell, 2005). Late-onset anxiety can also be attributed to adverse events, such as increased medical problems, widowhood, displacement to traditional settings resulting from complicated medical conditions, cognitive impairment, and physical disabilities (Cone, 2008). Loss of social support provokes fear and pain and may make older adults reluctant to form new friendships, leading them to isolation and increased anxiety. This increasing isolation may be true especially for older adults in nursing homes. Despite the high prevalence of anxiety among older adults, anxiety remains understudied among this population (Wetherell, 1998).

Appropriate understanding of the risk factors associated with anxiety and depression will enhance the detection of the high prevalence of depression and anxiety exists among older adults. Though depression and anxiety may share common risk factors among older adults, few researchers have focused on risk factors for anxiety in later life (Vink et al., 2008) and older adults residing in the nursing home. Rather, most researchers have focused on community-dwelling older adults. Ten percent of older adults living in nursing homes present with clinical depression, whereas 6\% have anxiety problems (Préville, Côte, Boyer, \& Hébert, 2004). 


\section{Depression and Anxiety Among Older Adults}

Depression is a common disorder afflicting older adults, especially those residing in nursing homes (Gonçalves, Albuquerque, Byrne, \& Pachana, 2009). However, although this may be the case, detection of depression among this population often remains unrecognized, but when recognized is undertreated or treated inadequately or inappropriately (R. N. Jones, Marcantonio, \& Rabinowitz, 2003). Depression is likely to persist unidentified among nursing home residents who are old-old (80 years of age and older), minorities, those who exhibit severe cognitive deficits, or those with limited social support (Mehta et al., 2008). Depression among older adults results in decreased quality of life increased medical problems, and mortality (Gonçalves et al., 2009). Researchers often believed late-life depression was part of normal aging, as well as an unavoidable symptom of growing old (Benek-Higgins, McReynolds, Hogan, \& Savickas, 2008). Depression in older adults may be overlooked because physicians may be focused on physiological factors in making a diagnosis (Katona, 2000). The misdiagnosis of depression among older adults with medical conditions is relatively common because symptoms of their health conditions often mimic symptoms of depression (Benek-Higgins et al., 2008). This misdiagnosis may be especially true for older adults residing in nursing homes because of the medical conditions that contributed to their placement. As a result, elders are often underserved and overlooked for psychological services (Myers \& Harper, 2004) and treatment is not always available to them. Additionally, some professionals believe this population does not benefit from services over time.

Anxiety, like depression, is common among older adults. A scarcity of research focuses on the prevalence of anxiety among this population, especially those residing in nursing homes (Smalbrugge, Pot, Jongenelis, Beekman, \& Eefsting, 2005). Of the research that has been conducted, researchers estimated the prevalence of anxiety among community-dwelling older adults to range between 2 and 19\% (Ayers, Sorrell, Thorp, \& Wetherell, 2007). Although a lack of research focused on anxiety among the elderly population in the past, in recent years, researchers have focused on the prevalence, nature, and consequences of stress (Bryant, Jackson, \& Ames, 2008). This research has resulted in conflicting findings, including the belief that anxiety manifests differently in younger people than older (Flint, 2005), whereas conflicting research suggested otherwise (Wetherell, Sorrell, Thorp, \& Patterson, 2005). Also, Flint (2005) indicated that anxiety and depression are comorbid disorders, whereas Wetherell et al. (2005) suggested the concurrence of anxiety and depression may be lower than each disorder on its own. Resolution of these controversies has not yet occurred; 
however, it is important to address the effects/consequences of anxiety among the older population.

\section{Hispanic Culture}

According to the 1991 U.S. Census, individuals of Hispanic descent over the age of 64 are the fastest growing population in the nation (Beyene, Becker, \& Mayen, 2002). Baxter, Bryant, Scarbro, and Shetterly (2001) found limited research focused on nursing home use among Hispanics, specifically those of Mexican American descent. About 2-3\% of Mexican American elders reside in a nursing home setting (Markides et al., 1996). The reason for this small percentage has much to do with the culture; family members care for most elders of Mexican descent at home. Culturally, Mexican Americans regard older adults with much respect, valuing them for their wisdom. Hispanics, specifically those of Mexican descent, have a close relationship with their elders and tradition holds that it is the moral obligation for the now adult children to care for elder adults. Therefore, Mexican Americans do not view nursing homes as a culturally practical alternative, but as a last resort if necessary.

In a study conducted by Eribes and Bradley-Rawls (1978), researchers indicated that older adults of Mexican origin would be more likely to use nursing homes if they were built in neighborhoods more highly populated by individuals of Mexican descent. Despite cultural values and traditions, families of older adults of Mexican origin are placing them in nursing homes. As a result, these individuals not only must endure the complications (physical and emotional) associated with aging but also accept a placement not customary of their culture. Therefore, research on this population is significant because it may enhance and further increase understanding of elders' needs, thereby promoting a better quality of life for them.

\section{Purpose}

The purpose of this non-experimental quantitative study was to examine the relationship between risk factors (gender, marital status, familial support, ADLs, and participation in nursing home activities) associated with depression and anxiety among elders of Mexican origin residing in nursing homes. Further analysis determined if risk factors associated with depression among this population were the same factors as those associated with anxiety among this population. By examining the relationship between risk factors and depression and anxiety in older adults of Mexican origin residing in nursing homes in a Texas-Mexico border city, this study offers physicians, psychologists, and other mental health professionals an understanding of the risk factors. Physicians may, therefore, be more willing to refer nursing 
home residents for psychological services; psychologists and other mental health professionals will discover a greater need for geropsychology.

\section{Research Questions and Hypotheses}

1. How well do the five individual risk factors (gender, marital status, familial support, ADLs, and participation in nursing home activities) predict depression among older adults of Mexican origin residing in nursing homes? How much variance on the GDS can be explained knowing these factors? What is the best predictor of depression: gender, marital status, familial support, ADLs, or participation in nursing home activities?

$H_{0} 1$ : For all correlations of the five individual risk factors, no predictive a relationship exists between individual risk factors, measured by the demographic questionnaire, and the construct of perceived depression, measured by the GDS, among older adults of Mexican origin residing in nursing homes.

$H_{\mathrm{a}} 1$ : For at least one of the correlations, a significant predictive relationship exists between the individual risk factors, measured by the demographic questionnaire, and the construct of depression, measured by the GDS, among older adults of Mexican origin residing in nursing homes.

2. How well do the five individual risk factors (gender, marital status, familial support, ADLs, and participation in nursing home activities) predict anxiety among older adults of Mexican origin residing in nursing homes? How much variance on the BAI can be explained knowing these factors? What is the best predictor of anxiety: gender, marital status, familial support, ADLs, or participation in nursing home activities?

$H_{0}$ 2: For all correlations of the five individual risk factors, no predictive a relationship exists between the individual risk factors, measured by the a demographic questionnaire and the construct of perceived anxiety measured by the BAI, among older adults of Mexican origin residing in nursing homes.

$H_{\mathrm{a}}$ 2: For at least one of the correlations, a significant predictive relationship exists between the individual risk factors, measured by the demographic questionnaire, and the construct of anxiety, measured by the BAI, among older adults of Mexican origin are residing in nursing homes.

\section{Research Design and Approach}

This quantitative study used a non-experimental design. Participants' responses to the researcher-developed demographic questionnaire yielded the potential risk factors. The GDS, developed by Yesavage et al. (1983), was used to assess the level of depression. The instrument was appropriate for use in this study due to its extensive use with older populations in community settings and long-term settings. Although the BAI developed by 
Beck and Steer (1993) was not designed to be used with older adults, the use of the BAI among this population has high internal consistency (Yochim, Mueller, June, \& Segal, 2011). Therefore, the BAI was the instrument of choice to assess the level of anxiety in older adults participating in this study. Furthermore, the MMSE-2 was administered to participants, which determined participants’ cognitive ability to take part in the study.

\section{Setting and Sample}

The sample for this study was drawn from four nursing homes located in a city on the border between Texas and Mexico. Participants were of various ages, ranging upward from 55, and of Mexican origin. Descriptive statistics was reported on these variables. Permission was sought from the administrators at each of the nursing homes before conducting the study. To be eligible for participation in the study, residents have to be 55 years of age or older, be able to communicate effectively in either Spanish or English, have no severe cognitive impairment (MMSE-2 $\geq 23$ ), and be of Mexican descent.

\section{Procedures}

Participants were recruited to voluntarily participate in the research study through hand-delivered invitations taken to their rooms announcing that a study is available to prospective participants. The invitation and eligibility requirements were verbally explained to the potential participants, and a written request containing a brief description of the study and the informed consent was provided. Potential participants were provided an index card with their room number and bed letter, and they were asked to deposit the card in a box at the nurses' station if they choose to participate. Once the informed consent form was signed, participants were provided the demographic survey and three screening instruments. The demographic survey was verbally administered if requested. The three psychometric screening instruments, also available in Spanish, were then administered.

\section{Demographic Characteristics of the Sample}

Participants were assessed on an individual basis during a month and a half long time frame. A total of 150 participants from four prospective nursing homes participated in the study, and all completed the instruments successfully. Of those who took part, 50 were male, and 100 were female. The majority of the participants were Mexican (53\%), and the remaining were Mexican-American (47\%). Of these participants, $47 \%$ were widowed, $27 \%$ were married, $15 \%$ were single, and $12 \%$ were divorced. Only $36 \%$ of the participants indicated receiving family support at least once a week, while $19 \%$ indicated daily support, $19 \%$ only twice a month, $10 \%$ of three 
times a week or at least once a month, and 6\% received family support twice a week.

Results indicated 38\% of the participants participated in daily activities with some (34\%) participating 2 to 3 times a week while $26 \%$ do not participate in any activities, $1 \%$ participate once a week, and less than $1 \%$ attended four times a week. With regards to ADLs, 96\% did not require assistance for eating, 3\% needed some aid, and 1\% required full support. For dressing, 43\% required no assistance, 28\% needed some assistance and 29\% required full support. Also, 47\% needed no assistance for toileting, 23\% required some aid and 30\% required full support. Finally, 48\% needed no assistance for transferring, 23\% required some assistance and 29\% required full assistance.

\section{Overview of Design and Procedures}

Depression and anxiety were assessed for each participant. Participants completed a mental status examination, two screening instruments, and one demographic questionnaire. The mental status examination was the first instrument administered and was used solely to determine the participants' cognitive ability to participate in the study (MMSE-2 cutoff score $\geq 23$ ). The mean and SD for the composite score of the MMSE-2 was $M=24.59$ and $S D=1.76$.

The second instrument administered was the GDS. The composite scores of symptom severity ranged from 0-4 none to mild depression (56\%), 5-9 moderate depression (30\%) and 10-15 severe depression (14\%). The mean and SD for the composite score of depression was $M=4.49$ and $S D=$ 3.98. The third instrument administered was the BAI. The composite scores of symptom severity ranged from 0-7 none to minimal anxiety (69\%), 8-15 mild anxiety (18\%), 16-25 moderate anxiety (10\%) and 26-63 severe anxiety (3\%). The mean and SD for the composite score of anxiety was $M=6.21$ and $S D=7.59$. The mean scores and standard deviations for the criterion and predictor variables are shown in Table 1.

Table 1 Means and Standard Deviations for Criterion and Predictor Variables ( $\mathrm{N}=150)$

\begin{tabular}{ccc}
\hline Variable & Mean & SD \\
\hline GDS & 4.49 & 3.98 \\
BAI & 6.21 & 7.59 \\
TotADL & 6.54 & 2.50 \\
& & \\
\hline
\end{tabular}

\section{Data Analyses}

Two different analyses were run. The first examined the predictive relationship of the five individual risk factors and depression. It also 
examined how much variance can be explained by the scores on the depression scale (GDS), as well as which risk factors were the best predictor of depression. The second examined the predictive relationship of the five individual risk factors and anxiety, along with the variance that can be explained by the scores on the anxiety scale (BAI) and determine which risk factors were the best predictors of anxiety.

Data analyses were conducted using SPSS 21.0 software. In the preliminary analysis, the assumptions of linearity and homogeneity of variance were assessed with scatter plots. The assumptions were met. Homoscedasticity was confirmed through an examination of standardized residual plots. The standardized residual scores were evenly distributed over predicted standardized over the GDS and BAI scores. Skewness and kurtosis of the variables were examined and indicated a normal distribution for both composites. An examination of Mahalanobis distances (Pallant, 2013), computed from the regression of the GDS and BAI, demonstrated the $M D=$ 1.25 to 10.39 failed to identify any outliers considered significant outliers at $M D=20.52(\alpha=.001)$. The assumption of absence of multicollinearity among predictor variables (gender, marital status, familial support, ADLs, and participation in activities) was assessed by examining the Variance Inflation Factors (VIF) and Tolerance statistics. Tolerance statistics ranged between $T=.89$ and $T=.97$, and all VIF were below 10 , ranging between 1.03 and 1.12 meeting the assumption of the absence of multicollinearity (Pallant, 2013).

\section{Significant Findings}

To test the hypotheses for the first research question, the predictor variables were entered into a multiple regression analysis with the GDS as the criterion variable. The results indicated the risk factors account for $9.1 \%$ of the variance of depression, as measured by the GDS. The overall regression (Table 2) was significant, $F(5,144)=2.89, p<.001$, Adjusted $R^{2}=.060$.

Table 2 Model Summary of Variance for Depression, as Measured by the GDS

\begin{tabular}{lcccccc}
$\mathrm{R}$ & $\mathrm{R}^{2}$ & Adjusted $\mathrm{R}^{2}$ & $F$ & $d f 1$ & $d f 2$ & $p$ Value \\
\hline $.302^{\mathrm{a}}$ & .091 & .060 & 2.89 & 5 & 144 & $.016^{\mathrm{a}}$
\end{tabular}

Note: ${ }^{a}$ Predictors: (constant), gender, marital status, familial support, ADLs, participation in activities.

Regression weights were examined and were shown in Table 3. Of the predictor variables, ADLs makes the only significant contribution ( $\beta$ $=.274, p<.001$ ). Thus, a high score on ADL (needs full assistance) predicts 
higher depression. Although this predictive relationship exists, the strength is not very strong. Based on the findings of the analysis, the null hypothesis for the first question, "For all correlations of the five individual risk factors, no predictive relationship exists between individual risk factors, measured by the demographic questionnaire, and the construct of perceived level of depression, measured by the GDS, among older adults of Mexican origin residing in nursing homes." was rejected. The alternate hypothesis was supported indicating a significant predictive relationship exists by at least one of the individual risk factors (ADLs) and the construct of depression. These findings suggest full assistance with ADLs predicts high levels of depression.

Table 3 Summary of Analysis for Variables Predicting Depression, as Measured by the GDS

\begin{tabular}{lccccc}
\hline Measure & $B$ & SE B & $\beta$ & $t$ & $p$ \\
\hline Gender & .586 & .707 & .070 & .829 & .408 \\
Marital status & -.285 & .282 & -.082 & -1.011 & .314 \\
Familial support & .319 & .180 & .146 & 1.772 & .079 \\
ADLs & .436 & .129 & .274 & 3.367 & .001 \\
Participation in & -.049 & .262 & -.015 & -.189 & .850 \\
activities & & & & .353 & .724 \\
Constant & .623 & 1.763 & & .353
\end{tabular}

Note. $\mathrm{B}=$ Unstandardized $\beta, \mathrm{SEM}=$ standard error of the mean for unstandardized $\beta$, Std $\mathrm{B}$ $=$ standardized $\beta$.

To examine the second hypothesis question and determine the extent in which the five individual risk factors predicted the construct anxiety, as measured by the BAI, another multiple regression analysis was conducted. The results of the analysis, shown in Table 4, indicated the risk factors account for $11.7 \%$ of the variance of anxiety. The overall regression was statistically significant, $\mathrm{F}(5,144)=3.83, p<.001$, Adjusted $R^{2}=.087$.

Table 4 Model Summary of Variance for Anxiety, as Measured by the BAI

\begin{tabular}{ccccccc}
\hline $\mathrm{R}$ & $\mathrm{R}^{2}$ & Adjusted $\mathrm{R}^{2}$ & $F$ & $d f 1$ & $d f 2$ & $p$ Value \\
\hline $.342^{\mathrm{a}}$ & .117 & .087 & 3.83 & 5 & 144 & $.003^{\mathrm{a}}$
\end{tabular}

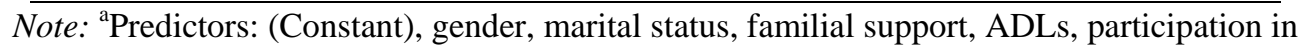
activities.

Regression weights were examined and were shown in Table 5. Of the predictor variables, gender made the largest unique contribution $(\beta$ $=.236)$, although family support $(\beta=.189)$, and ADLs $(\beta=.176)$, also made statistically significant contributions. Thus, females $(M=7.4)$ tended to have higher anxiety scores than males $(M=3.82)$. Individuals with more frequent 
family support had lower anxiety, and those with higher ADLs scores (needs full assistance) had higher anxiety scores. Based on the findings of the analysis, the null hypothesis for the second question, "For all correlations of the five individual risk factors, no predictive relationship exists between individual risk factors, measured by the demographic questionnaire, and the construct of perceived level of anxiety, measured by the BAI, among older adults of Mexican origin residing in nursing homes." was rejected. The alternate hypothesis was supported indicating a significant predictive relationship exists by at least one of the individual risk factors (gender, familial support, and ADLs) and the construct of anxiety. These findings suggest gender strongly predicts high levels of anxiety, as did complete assistance with ADLs while frequent family support predicts low levels of anxiety.

Table 5 Summary of Analysis for Variables Predicting Anxiety, as Measured by the BAI

\begin{tabular}{|c|c|c|c|c|c|}
\hline & Measure $B$ & $S E B$ & $\beta$ & $t$ & $p$ \\
\hline Gender & 3.787 & 1.329 & .236 & 2.849 & .005 \\
\hline Marital status & .561 & .530 & .085 & 1.058 & .292 \\
\hline Familial suppor & rt .786 & .338 & .189 & 2.324 & .022 \\
\hline ADLs & .536 & .243 & .176 & 2.203 & .029 \\
\hline $\begin{array}{l}\text { Participation in } \\
\text { activities }\end{array}$ & -.341 & .492 & -.055 & -.692 & .490 \\
\hline Constant - & -6.855 & 3.316 & & -2.068 & .040 \\
\hline
\end{tabular}

Note. $\mathrm{B}=$ Unstandardized Beta, $\mathrm{SEM}=$ standard error of the mean for unstandardized Beta, Std B = standardized Beta.

\section{Discussion}

This study and its importance were justified by the scarcity of empirical data in the literature regarding nursing home residents, especially those of a minority population, and their risk factors associated with depression and anxiety. The risk factors associated with depression and anxiety among community-dwelling older adults have been well documented (Vink et al., 2008). However, some of the research demonstrated contradictory or inconclusive findings. For example, Heun and Hein (2005) found gender, age, subjective memory impairment, previous history of anxiety disorders, and somatoform disorders were all risk factors associated with depression among community-dwelling older adults. In contrast, Vink et al. (2008) conclude that age, memory impairment or previous psychopathology were not risk factors associated with depression; instead, they determined that chronic disease, poor self-perceived health, being unmarried, inadequate coping strategies, functional disability and smaller set of family and friends were the relevant risk factors. According to Cole and 
Dendukuri (2003), age, lower education level, being unmarried and poor social support were not seen as risk factors for depression.

The literature on risk factors for anxiety among this population is limited. According to Vink et al. (2008), few studies have focused on risk factors associated with anxiety. Those studies that have focused on stress demonstrated variability with regards to conclusions and outcomes (Beekman et al., 2000; Vink et al., 2008). Furthermore, there is a limited amount of research focused on nursing home use among Hispanics, specifically that of Mexican American decent (Baxter et al., 2001). It is estimated that 2\% to 3\% of Mexican-American elderly reside in a nursing home setting (Markides et al., 1996). However, these numbers are projected to rise with the baby boomer generation. Therefore, understanding the risk factors, such as gender, marital status, ADLs, participation in activities and familial support, associated with depression and anxiety among this population was imperative to develop adequate prevention and treatment plans.

\section{Interpretation of the Findings}

Based on the findings of the regression analyzes the null hypotheses regarding the predictive relationships between the five individual risk factors (gender, marital status, familial support, and ADLs) and depression, as well as the predictive relationships between the five different risk factors and anxiety, were rejected, and alternative hypotheses were retained. The overall results support the premise that at least one particular risk factor (full assistance with ADLs) strongly predicts high levels of depression among older adults of Mexican origin residing in nursing homes. Results further support that at least one of the individual risk factors (gender and full assistance with ADLs) strongly predicts high levels of anxiety, while frequent family support predicts lower levels of stress, among older adults of Mexican origin residing in nursing homes.

\section{Limitations of the Study}

One limitation of this study was a reliance on the researcher to administer the assessment tools orally due to the participants' request stemming from their physical disabilities (e.g. poor vision, paralysis, severe arthritis, and tremors) that did not allow them to self-administer. As a result, there were no systematic means to determine if the participants were in any way influenced by the researcher. Another limitation of the study relates to mood and timeframe of when participants' answered the questionnaires, as this was not under the control of the researcher and may have influenced the responses. Various conditions could account for the replies/results obtained. 
Since the study was limited to data based on self-reports and demographic information, other latent constructs of perceived depression and anxiety, such as physical diagnoses, medication, or prior mental illness, were not explored. The individual risk factors were limited to gender, marital status, familial support, ADLs, and participation in nursing home activities measured by the demographic questionnaire. Unknown is whether other unmeasured variables moderated the variables under study.

\section{Recommendations for Further Research}

This study demonstrated older adults of Mexican origin residing in nursing homes who required full assistance with ADLs showed higher levels of depression and anxiety. Being female was also predictive of high levels of stress while more frequent family support was predictive of low levels of anxiety. The predictive relationship between female gender and stress may be due to females, especially in the given culture, excessive worry about their families, physical ailments, among other things they may not have any or much control over. Nursing home placement limits the control residents' have within their reach. This speculation could be the contributor to this finding. Further studies with larger populations are recommended to provide additional insights into the risk factors that may be more predictive of depression and anxiety. Results from minority, specifically Hispanic, residents residing in nursing homes would provide support for this study's findings. Further research may consider widening the selection of risk factors and not limiting them to only demographics. Studies might also consider focusing on medical diseases, medications, history of family mental illness and history of individual mental illness as risk factors for depression and anxiety among this population.

\section{Implications for the Profession}

This study focused on a sample $(N=150)$ of older adults of Mexican origin residing in nursing homes located in a Texas-Mexico border city. The research was designed to collect data to examine the predictive relationship between five individual risk factors and depression and anxiety. The results of two standard multiple regression analyses determined a significant predictive relationship existed between ADLs (full assistance required) and high levels of depression and anxiety. Also, female gender was predictive of high levels of stress, while more frequent familial support was predictive of low levels of anxiety. A significant predictive relationship was not found between gender, marital status, familial support or participation in nursing homes and level of depression. Also, an important predictive relationship was not found between marital status or involvement in nursing homes and level of anxiety. 
These findings suggest that older adults of Mexican origin residing in nursing homes who require full assistance with eating, dressing, toileting, and transferring are more likely to experience high levels of depression and anxiety. Females, of this given population, are more liable to experience high levels of stress, while those individuals, of this given population, who have more frequent family support experience low levels of anxiety. Based on these results, it seems pertinent to promote more family involvement. This may be achieved by increasing communication between family and nursing home staff regarding the care of their loved ones. Also, the nursing home administration may consider organizing more family activities that will entice family members to be more proactive and involved. When there is more family participation in a resident's life, the resident's risk of developing emotional distress should be minimized.

\section{References:}

Ayers, C. R., Sorrell, J. T., Thorp, S. R., \& Wetherell, J. L. (2007). Evidence-based psychological treatments for late-life anxiety. Psychology and Aging, 22, 8-17.

Baxter, J., Bryant, L. L., Scarbro, S., \& Shetterly, S. M. (2001). Patterns of rural Hispanic and non-Hispanic White health care use: The San Luis Valley Health and Aging Study. Research on Aging, 23, 37-59.

Beck, A. T., \& Steer, R. A. (1993). Beck Anxiety Inventory Manual. San Antonio, TX: Psychological Corporation.

Beekman, A. T. F., de Beurs, E., van Balkom, A. J. L. M., Deeg, D. J. H., van Dyck, R., \& van Tilburg, W. (2000). Anxiety and depression in later life: Co-occurrence and communality of risk factors. The American Journal of Psychiatry, 157, 89-95.

Benek-Higgins, M., McReynolds, C. J., Hogan, E., \& Savickas, S. (2008). Depression and the elder person: The enigma of misconceptions, stigma, and treatment. Journal of Mental Health Counseling, 30(4), 283-296.

Beyene, Y., Becker, G., \& Mayen, N. (2002). Perception of aging and sense of well-being among Latino elderly. Journal of Cross-Cultural Gerontology, 17, 155-172.

Brandburg, G. L., Symes, L., Mastel-Smith, B., Hersch, G., \& Walsh, T. (2013). Resident strategies for making a life in a nursing home: A qualitative study. Journal of Advanced Nursing, 69, 862-874.

Bryant, C., Jackson, H., \& Ames, D. (2008). The prevalence of anxiety in older adults: Methodological issues and review of the literature. Journal of Affective Disorders, 109, 233-250. 
Chavez-Korell, S., Rendón, A. D., Beer, J., Rodriguez, N., Garr, A. D., Pine, C. A., ... Malcolm, E. (2012). Improving access and reducing barriers to depression treatment for Latino elders: Un nuevo amanecer [a new dawn]. Professional Psychology: Research and Practice, 43, 217-226.

Choido, L. K., Kanten, D. N., Gerety, M. B., Mulrow, C. D., \& Cornell, J. E. (1994). Functional status of Mexican-American nursing home residents. Journal of the American Geriatrics Society, 42 (3), 293-296.

Cole, M. G., \& Dendukuri, N. (2003). Risk factors for depression among elderly community subjects: A systematic review and meta-analysis. The American Journal of Psychiatry, 160, 1147-1156.

Cone, W. (2008). Aging, mental health and long-term care. Retrieved from http://www

.continuingedcourses.net/active/courses/course041.php

Cummings, S. M., Kropf, N. P., Cassie, K. M., \& Bride, B. (2004). Evidence-based treatment for older adults. Journal of Evidence-Based Social Work, 1, 53-81.

Eribes, R. A., \& Bradley-Rawls, M. (1978). The underutilization of nursing home facilities by Mexican-American elderly in the Southwest. The Gerontologist, 18, 363-371.

Federal Interagency Forum on Aging-Related Statistics. (2012, June). Older Americans 2012: Key indicators of well-being. Retrieved from http://www.agingstats.gov

/agingstatsdotnet/Main_Site/Data/2012_Documents/Docs/EntireChartbook.p df

Flint, A. J. (2005). Anxiety and its disorders in late life: Moving the field forward. The American Journal of Geriatric Psychiatry, 13, 3-6.

Gonçalves, D. C., Albuquerque, P. B., Byrne, G. J., \& Pachana, N. A. (2009). Assessment of depression in aging contexts: General considerations when working with older adults. Professional Psychology: Research and Practice, 40, 609-616.

Heun, R., \& Hein, S. (2005). Risk factors of major depression in the elderly. European Psychiatry, 20, 199-124.

Jones, E. D., \& Beck-Little, R. (2002). The use of reminiscence therapy for the treatment of depression in rural-dwelling older adults. Issues in Mental Health Nursing, 23, 279-290.

Jones, R. N., Marcantonio, E. R., \& Rabinowitz, T. (2003). Prevalence and correlates of recognized depression in U.S. nursing homes. Journal of the American Geriatrics Society, 51, 1404-1409.

Karel, M. J., Holley, C. K., Whitbourne, S. K., Segal, D. L., Tazeau, Y. N., Emery, E. E., ... Zweig, R. A. (2012). Preliminary validation of a tool to assess competencies for professional geropsychology practice. Professional Psychology: Research and Practice, 43, 110-117. 
Katona, C. (2000). Managing depression and anxiety in the elderly patient. European Neuropsychopharmacology, 10, S427-S432.

Kieffer, K. M., \& Reese, R. J. (2002). A reliability generalization study of the Geriatric Depression Scale. Educational and Psychological Measurement, 62, 969-994.

Le Roux, H., Gatz, M., \& Wetherell, J. L. (2005). Age at onset of generalized anxiety disorder in older adults. The American Journal of Geriatric Psychiatry, 13, 23-30.

Markides, K. S., Stroup-Benham, C. A., Goodwin, J. S., Perkowski, L. C., Lichtenstein, M., \& Ray, L. A. (1996). The effect of medical conditions on the functional limitations of Mexican-American elderly. Annals of Epidemiology, 6, 386-391.

Mehta, M., Whyte, E., Lenze, E., Hardy, S., Roumani, Y., Subashan, P., ... \& Studenski, S. (2008). Depressive symptoms in late life: Associations with apathy, resilience, and disability vary between young old and old-old. International Journal of Geriatric Psychiatry, 23, 238-243.

Mulrow, C. D., Chiodo, L. K., Gerety, M. B., Lee, S., Basu, S., \& Nelson, D. (1996). Function and medical comorbidity in South Texas nursing home residents: Variations by ethnic group. Journal of the American Geriatrics Society, 44, 279-284.

Myers, J. E., \& Harper, M. C. (2004). Evidenced-based effective practices with older adults. Journal of Counseling \& Development, 82, 207-218.

National Institutes of Health. (2002). Long-term care recipients: Quality of life and quality of care research. Retrieved from http://grants.nih.gov/grants/guide/pa

-files/PA-02-162.html

Pallant, J. (2013). SPSS survival manual: A step by step guide to data analysis using IBM SPSS (5th ed.). New York, NY: The McGraw-Hill Companies

Préville, M., Côte, G., Boyer, R., \& Hébert, R. (2004). Detection of depression and anxiety disorders by home care nurses. Aging \& Mental Health, 8, 400-409.

Smalbrugge, M., Pot, A. M., Jongenelis, K., Beekman, A. T. F., \& Eefsting, J. A. (2005). Prevalence and correlates of anxiety among nursing home patients. Journal of Affective Disorders, 88, 145-153.

Tatchell, T., Jordan, T. R., Waite, P. J., \& Tatchell, R. H. (2003). Transmissive reminiscence therapy with college students and institutionalized senior adults. Journal of Intergenerational Relationships, 1(4), 35-52. 
Texas Department on Aging, Office of Aging Policy and Information. (2002, September). Older adult profile: Hispanics in Texas. Paper presented at the National Hispanic Council on Aging: Elder Abuse and Victimization Summit, La Joya Senior Citizens Center, La Joya, TX.

Texas Health and Human Services System. (2010). Health and human services system strategic plan 2011-2015.

U.S. Department of Health \& Human Services, Administration on Aging. (2009). A statistical profile of Hispanic older Americans aged 65+.

Vink, D., Aartsen, M. J., \& Schoevers, R. A. (2008). Risk factors for anxiety and depression in the elderly: A review. Journal of Affective Disorders, 106, 29-44.

Wetherell, J. L. (1998). Treatment of anxiety in order adults. Psychotherapy, 35, 444-458.

Wetherell, J. L., Sorrell, J. T., Thorp, S. R., \& Patterson, T. L. (2005). Psychological interventions for late-life anxiety: A review and early lessons from the CALM study. Journal of Geriatric Psychiatry and Neurology, 18, 72-82.

Yesavage J. A., Brink T. L., Rose T. L., Lum, O., Huang, V., \& Leirer, V. O. (1983). Development and validation of a geriatric depression screening scale: A preliminary report. Journal of Psychiatric Research, 17, 37-49.

Yochim, B. P., Mueller, A. E., June, A., \& Segal, D. L. (2011). Psychometric properties of the Geriatric Anxiety Scale: Comparison to the Beck Anxiety Inventory and Geriatric Anxiety Inventory. Clinical Gerontologist, 34, 2133. 